\title{
DOUTRINA
}

\section{MORALIDADE ADMINISTRATIVA}

CAIO TÁCITO*

A presença da moralidade administrativa em norma de equivalência constitucional surge, pioneiramente, entre nós, com o Decreto no 19.398, de 11 de novembro de 1930, que instituiu o Governo Provisório da República dos Estados Unidos do Brasil quando a Revolução de outubro do mesmo ano dissolve o Congresso Nacional e as Assembléias Legislativas Estaduais até que se estabeleça a reorganização institucional com a convocação de Assembléia Constituinte, da qual vai emanar a Constituição de 1934.

$\mathrm{O}$ art. $7^{\circ}$ da lei mantém em vigor as leis, obrigações e direitos na esfera pública, "salvo os que, submetidos a revisão, contravenham o interesse público e a moralidade administrativa".

É, contudo, a Constituição de 1988 que realça e destaca, em diversos de seus preceitos, a importância da moralidade administrativa entre os pressupostos máximos do sistema constitucional.

$\mathrm{Na}$ enumeração dos princípios básicos a que devem obediência a administração pública direta e indireta de qualquer dos poderes da União, Estados, Distrito Federal e Municípios, o art. 37 inscreve, declaradamente, a moralidade, a par da legalidade, da impessoalidade e da publicidade, aos quais a emenda Constitucional $\mathrm{n}^{2} 19$, de 4 de junho de 1998, vem acrescer o princípio da eficiência.

Fiel ao modelo federal, as Constituições Estaduais igualmente incorporam o princípio da moralidade (Acre, art. 27; Amazonas, art. 104, § 1ㅇ; Pará, art. 20; Maranhão, art. 19; Piauí, art. 39; Ceará, art. 154; Rio Grande do Norte, art. 26; Paraíba, art. 30; Pernambuco, art. 97; Bahia, art. 13; Alagoas, art. 42; Sergipe. art. 25; Espírito Santo, art. 32; Rio de Janeiro, art. 77; São Paulo, art. 111; Paraná, art. 27; Santa Catarina, art. 16; Rio Grande do Sul, art. 19; Goiás, art. 92; Mato Grosso do Sul, art. 25).

* Professor Emérito da Universidade do Estado do Rio de Janeiro.

R. Dir. Adm.,

Rio de Janeiro, 218: 1-10,

out./dez. 1999 
$\mathrm{Na}$ Constituição Federal a lesão à moralidade administrativa é fundamento expresso para a anulação de ato lesivo ao patrimônio público pela via da ação popular (art. 5․ inciso LXXVIII) e o art. 14. § 9o admite, em defesa da moralidade para o exercício do mandato eleitoral, possa lei complementar estabelecer a inelegibilidade em proteção à probidade administrativa que é igualmente resguardada na enumeração dos crimes de responsabilidade atribuíveis ao Presidente da República (art. 85. $\mathrm{n}^{\mathrm{Q}}$ V), sobre os quais dispõe o art. 9o da Lei no 1.709. de 10 de abril de 1950.

Atos de improbidade administrativa podem conduzir à cassação de direitos políticos, perda de função pública. indisponibilidade de bens e obrigação de ressarcimento ao erário, como prevê o $\S 4^{\circ}$ do art. 37 , combinado com o art. $15, n^{0} \mathrm{~V}$. A Lei $\mathrm{n}^{\circ}$ 8.429. de 2 de junho de 1992 regula as sanções aplicáveis pelos atos de improbidade administrativa.

O decoro parlamentar é, a seu turno. requisito elementar ao exercício de mandato político, sujeito à perda em caso de procedimento com ele incompatível (art. 55, no II) no qual se insere a percepção de vantagens indevidas ( $\$ 1^{10}$ do art. 55).

O provimento de cargos de Ministro do Tribunal de Contas da União exige o requisito de idoneidade moral e de reputação ilibada (art. $73, \S 1^{\circ}$. art. II) e esta última qualidade é, a par de notável saber jurídico, elemento moral indispensável para o acesso aos cargos de Ministro do Supremo Tribunal Federal e de Ministro do Superior Tribunal de Justiça (art. 101; art. 104, parágrafo único).

Entre os valores fundamentais colocados como diretrizes na Constituição figura a dignidade da pessoa humana (art. $\mathrm{I}^{\circ}, \mathrm{n}^{\mathrm{o}}$ III, art. 226, $7^{\circ}$ e art. 227), constituindo finalidade essencial da República construir uma sociedade justa (art. 3ํㅡ, ํㅛ I), com a garantia de inviolabilidade da honra (art. $5^{2}, n^{\circ} X$ ) e expressão da cidadania, elemento básico do Estado Democrático de Direito 9 art. 1ํㅡ, noII).

\section{II}

A moralidade que integra o controle da legalidade tem, por excelência, um sentido sociológico, como destaca CARBONIER (Droit Civil - tomo I, 22/30).

No campo da Administração Pública tem como diretrizes o dever de boa administração, a garantia dos bons costumes e a noção de equiidade no confronto entre o interesse público e o dos administrados.

A crise política que levou ao impeachment do Presidente Collor colocou em destaque o princípio da moralidade ameaçado ou violado pela corrupção administrativa.

A corrupção tem raízes seculares na história dos costumes políticos, aqui e alhures. De logo acodem à lembrança os sermões de Vieira sobre a conjugação do verbo rapio e o modelar tratado sobre a Arte de Furtar com que o autor anônimo diagnosticou objetivamente os hábitos da burocracia colonial.

Em verdade. o desvio ético coincide com a história da humanidade. O primeiro ato de corrupção pode ser imputado à serpente seduzindo Adão com a oferta da maçã. na troca simbólica do paraíso pelos prazeres ainda inéditos da carne. A 
decadência de Roma Imperial foi estimulada pela corrupção dos costumes. inclusive na vida política.

Manoel Figueiredo Ferraz, em artigo publicado na Revista de Direito Administrativo (volume 72/37). documentou a corrupção eleitoral no Império Romano. no qual a severidade das leis proibitivas (as chamadas leis de ambitu) não impediu a permanência da compra de votos e a manipulação da publicidade em benefício dos candidatos.

O auxílio à fuga de escravos, ou a corrupção destes estimulada por terceiros, era objeto, em Roma, de especial ação de reparação (actio servo corruptio), obrigando o autor a indenizar o proprietário do escravo pelo dobro do dano causado.

Nas ditaduras asiáticas e latino-americanas a limitação das liberdades políticas se associou aos negócios escusos, propiciadores de respeitáveis fortunas que alimentam contas bancárias secretas.

Na prática norte-americana a corrupção no serviço público tem sido documentada na literatura política e jurídica.

São conhecidos os escândalos que marcaram a administração do Presidente Grant, desde a chamada quadrilha do uísque, com a sonegação de impostos e as concessões lucrativas para explorar o comércio, que levaram ao processo de $\mathrm{im}$ peachment do Ministro da Guerra William Belknap. A administração do presidente Harding ficou marcada pelo escândalo de arrendamento das reservas de óleo do Teapot Dome, que se tornou o símbolo da corrupção, levando à morte o Presidente pela exaustão psicológica.

$\mathrm{Na}$ era Truman foram anotados casos de corrupção que inspiraram inquéritos parlamentares e no governo Eisenhower elementos de sua administração foram levados à renúncia pela conduta imprópria em negócios públicos.

A corrupção na Municipalidade de Nova York foi especialmente examinada em artigo publicado na revista Urban Affairs Quartely — junho de 1992. Estudo sobre o noticiário de inspeções administrativas de 1940 a 1980 evidencia 14 casos de corrupção, ou seja, a média de um escândalo a cada dois anos e meio. As várias leis municipais que ali visam a garantir a ética na administração e a coibir os abusos de poder das autoridades não são a rigor executadas, segundo os depoimentos dos autores, que aconselham a criação de uma promotoria especial para o combate à corrupção no governo.

Alguns episódios ilustram a história da corrupção na cidade de Nova York.

O Prefeito O'Dwyer (1946-1950) foi levado a renunciar pela prática de corrupção eleitoral.

$\mathrm{Na}$ administração do Prefeito John Lindsay as acusações de corrupção em obras públicas levaram à condenação criminal do responsável pelo abastecimento de água.

Informam os autores que, desde 1940. nenhuma administração municipal escapou à pecha da corrupção, culminando com os escândalos da administração do Presidente Edward Koch (a 978-1980).

Mais expressiva é a tolerância com a conduta ilícita de funcionários que solicitam vantagens para o cumprimento de deveres de ofício, qualificada como honest graft (suborno honesto), algo que poderá corresponder na gíria nacional, ao tolerado hábito de vender facilidades, ou. em imagem gastronômica, a comer bola para digerir 
pretensões das partes. Aquilo que. na gíria de língua espanhola, é a mordida. na prática italiana a bustarella (a luva), ou, na terminologia indiana, speed money (dinheiro rápido).

O presidente Nixon foi levado à renúncia, na iminência de ser afastado do poder em processo de impeachment, em face de comprovados abusos de poder, entre os quais a mal explicada origem de recursos na reforma de sua casa de campo.

O mundo comercial é, por natureza, o grande palco de fraudes e negócios escusos, na medida em que o risco e o lucro são as duas alavancas em que se inspira a alma do comércio. Em Roma, Mercúrio era, ao mesmo tempo, o Deus dos comerciantes e dos ladrões.

A história da sociedades mercantis está semeada de escândalos financeiros, de tal modo que, na expressão de Ihering, o Conselhos de Administração das S. A. abrigam mais crimes e criminosos que as penitenciárias.

Quem não se lembra, entre nós, do encilhamento, no início da República, e, mais modernamente, das filipetas, do "boom" manipulado das bolsas em 1970, e, com atualidade, a conduta especulativa que inspirou a instauração da CPI sobre o sistema financeiro.

Poder e lucro são o estímulo da corrupção nos negócios financeiros e nas fraudes tributárias em que se entrelaçam fiscais e fiscalizados.

A lei combate a concorrência desleal e os abusos de poder econômico, documentados nos inquéritos do Banco Central e da Comissão de Valores Mobiliários.

No campo eleitoral, a compra de votos, em troca de favores, servia de base ao poder político dos coronéis, a que Victor Nunes leal dedicou um livro modelar e clássico sobre "Coronelismo, enxada e voto". As nomeações abundantes de correligionários, antes ou depois das eleições, caracterizavam os testemunhos políticos, repudiados na jurisprudência do Supremo Tribunal Federal na década de 60 (Revista de Direito Administrativo, vol. 59/338). E a força da publicidade ilícita, que permite a criação de mitos e a falsidade de denúncias escandalosas, está a reclamar um estudo profundo sobre as deformações do processo eleitoral e a participação da mídia.

No âmbito da Administração Pública, a corrupção é definida como a conduta ilícita do servidor que aceita ou solicita vantagens para a prática de ato de ofício. Assim se identifica a figura penal da corrupção passiva.

A hipótese é, por natureza, a de um crime bilateral que supõe a ação de outro agente, externo à Administração, que, pela oferta ou promessa de vantagem, igualmente ingressa no campo penal, como autor do crime de corrupção ativa. São dois delitos de concurso necessário, ambos autônomos, que, no entanto, reciprocamente se condicionam. À ação de quem recebe corresponde a ação de quem dá ou oferece. Tanto a corrupção ativa como a passiva se distinguem como própria ou imprópria. A primeira supõe a violação de um dever funcional. Na segunda, embora lícito o ato de ofício, a percepção de vantagem tipifica o crime. $O$ bem jurídico protegido é tanto a regularidade do serviço como a moralidade administrativa. A coação do funcionário sobre o administrado ou o contribuinte, extorquindo-lhe vantagem ilícita, formaliza o crime de concussão (expressão cujo étimo concutere representa o ato de sacudir a árvore para extrair-lhe os frutos. A tolerância com os faltosos ou omissos identifica o crime de condescendência criminosa. Igualmente o exercício irregular 
da função pública para alcançar interesse pessoal tipifica o crime de prevaricação. A seu turno, a interferência do funcionário em matéria estranha à sua competência para favorecer as partes interessadas define o crime de advocacia administrativa.

O combate à corrupção conduz à responsabilidade penal (crimes funcionais acima descritos), assim como à responsabilidade administrativa e, subsidiariamente, à responsabilidade civil do funcionário público.

$\mathrm{Na}$ instância judiciária, a par dos processos criminais, a ação popular e a ação civil pública facultam a iniciativa popular, ou do Ministério Público, como instrumento de controle da legalidade nos atos da Administração Pública e se especializam no combate à corrupção e a seus efeitos danosos ao patrimônio público.

A Constituição republicana de 1891 firmou o princípio da responsabilidade dos funcionários públicos pelos abusos e omissões em que incorressem no exercício dos cargos, assim como pela indulgência ou negligência em não responsabilizarem seus subordinados. Igual preceito se repete nas Constituições seguintes. A carta de 1946 aditou outra norma visando a reprimir o enriquecimento ilícito na função pública com as sanções de sequiestro e perdimento de bens. A partir de 1957 foi a matéria regulada em lei ordinária: primeiramente a Lei $\mathrm{n}^{\mathrm{O}} 3.164$, de $1^{\text {ㅇ }}$ de junho de 1957 , sucedida pela lei $\mathrm{n}^{\mathrm{2}} 3.502$, de 21 de dezembro de 1958 . Ambas foram substituídas pela Lei $\mathrm{n}^{\circ} 8.459$, de 2 de junho de 1992 que regula o procedimento administrativo e judicial em casos de improbidade no exercício do mandato, cargo, emprego ou função na administração direta, indireta ou fundacional. São definidos os casos de improbidade que importem enriquecimento ilícito ou causem prejuízo ao erário, facultada a qualquer pessoa a iniciativa de representação. A atual Constituição, mais severa, sanciona como assinalado, a prática de atos de improbidade com a suspensão de direitos políticos, a perda da função pública, a indisponibilidade dos bens e a obrigação de ressarcir ao erário, sem prejuízo da ação penal cabível (art. 37, § 4º).

Mais construtiva, porém, do que a sanção de desvios de conduta funcional será a adoção de meios preventivos que resguardem a coisa pública de manipulações dolosas ou culposas. Mais valerá a contenção que a repressão de procedimentos ofensivos à moralidade administrativa. Os impedimentos legais à conduta dos funcionários públicos e as incompatibilidades de parlamentares servem de antídoto às facilidades marginais que permitem a captação de vantagens ilícitas. A lei - e já agora a Constituição - obriga a prévia licitação para o compromisso de despesas e submetem a controle os contratos administrativos, assim como a distribuição de publicidade oficial. A obrigatoriedade de concursos públicos favorece a seleção pelo mérito no acesso aos cargos públicos. A atual Constituição estimula, ainda, a participação popular no controle da legalidade e da legitimidade dos atos da Administração Pública. A ação popular, como a ação civil pública, são instrumentos adequados ao combate de ilicitudes e malversações mediante a contenção de abusos do poder administrativo.

Entre os meios preventivos, em garantia da boa gestão orçamentária, avança historicamente a criação do Tribunal de Contas, como fiscal da exação nas obrigações financeiras assumidas pelo Poder Público.

Ainda no Império, Manoel Alves Branco propunha. em 1845, a criação de um Tribunal de Contas, inspirado no modelo europeu. O projeto de lei não prosperou 
e. conforme o diagnóstico de Rui Barbosa. "dormiu o bom sono de que raramente acordam as idéias úteis" (Comentário à Constituição Federal. vol. 6, pág. 431).

Com o advento da República e pela iniciativa de Rui. então Ministro da Fazenda, nasceu o Tribunal de Contas, ainda na fase do Governo Provisório e a novidade foi incorporada à Constituição de 1891, cujo art. 89 autorizou a instituição de "um tribunal de contas para liquidar as contas da receita e despesa e verificar a sua legalidade, antes de serem prestadas ao Congresso".

Rui definiu em palavras, que se tornaram clássicas, a finalidade da instituição:

"Convém levantar entre o poder que autoriza periodicamente a despesa e o poder que quotidianamente a executa, um mediador independente, auxiliar de um e de outro, que comunicando com a legislatura e intervindo na administração, seja não só o vigia como a mão forte da primeira sobre a segunda, obstando a perpetração das infrações orçamentárias por um veto oportuno aos atos do Executivo que, direta ou indireta, próximo ou remotamente, discrepem da linha rigorosa das leis de finanças".

As sucessivas Constituições da República conservaram a ampliaram a presença do Tribunal de Contas na competência de controle da despesa pública e da moralidade administrativa.

A Constituição de 1934 conferiu-lhe a missão de acompanhar a execução orçamentária e de julgar as contas dos responsáveis por dinheiros ou bens públicos (art. 99), impondo o prévio registro de contratos que, por qualquer modo, interessarem à receita ou à despesa, como requisito de serem tidos por perfeitos e acabados, como em geral, qualquer ato administrativo de que resultasse obrigações de pagamento pelo Tesouro nacional, ou à sua conta. A recusa de registro teria caráter proibitivo, salvo autorização especial do Presidente da República sujeita a revisão pela Câmara de Deputados (art. 101 e $\$ \S 1^{\circ}$ e $2^{\circ}$ ).

A Constituição de 1937, em seu art. 114, manteve a competência do Tribunal de Contas, que a Constituição de 1946 ratificou (art. 77).

A Constituição de 1967 , emendada em 1969, conserva o papel de relevo do Tribunal de Contas no processo de fiscalização financeira e orçamentária, como órgão auxiliar do Congresso Nacional, no controle externo das finanças públicas (art. 71).

A este quadro da posição do Tribunal de Contas a Constituição em 1988 trouxe nova fisionomia dinamizando a presença tradicional do órgão de controle.

A fiscalização adquire campo mais amplo. Mais do que apenas financeira e orçamentária alcança igualmente feição contábil, operacional e patrimonial, compreendendo todas as entidades da administração direta e indireta, inclusive fundações e sociedades instituídas e mantidas pelo Poder Público.

E. mais ainda, o controle a ser exercido pelo Congresso Nacional, com o auxílio do Tribunal de Contas, vai além da legalidade. Dirige-se também à legitimidade e à economicidade na gestão financeira, dilatando-se ao exame da aplicação de subvenções e aos casos de renúncia de receitas, ou seja. aos favores de incentivos fiscais (arts. 70 e 71). 
No direito francês o conceito da moralidade como integrante da legitimidade do exercício de competência administrativa teve como primeiro intérprete MAURICE HAURIOU que, em comentário aos arestos de 1914 do Conselho de Estado nos casos Gomel e Didier, acentuava que "a noção do excesso de poder é mais extensa do que a da legalidade; corresponde à moral que é mais extensa que o Direito" ( $\mathrm{La}$ jurisprudence administrative de 1892 à 1929 - tomo II, p. 375). E, analisando decisão que ordenava novo pronunciamento ministerial sobre pretensão de um particular, diagnosticava "um apelo eloqüente à moralidade administrativa" (ob. cit. p. 397).

Foi, todavia, em sucessivas edições de seu "Précis de Droit Administratif", notadamente a $11^{\mathbf{a}}$ edição (de 1927), que o mestre francês apontou a moralidade administrativa como elemento integrante do "detournement de pouvoir" (ob. cit. p. 347).

O tema do controle jurisdicional da moralidade administrativa, pela via do recurso de excesso de poder, foi amplamente estudado em livro de HENRI WELTER, especialmente dedicado ao tema (Le contrôle jurisditionel de la moralité administrative - 1919).

O controle dos motivos determinantes do ato administrativo, visando a definir sua compatibilidade com a finalidade legal, leva a que o dever de boa administração, na visão do autor, identifique a regra de existência da moralidade administrativa como elemento vinculativo da ação do administrador (ob. cit. p. 77).

A apreciação obrigatória do fim a ser alcançado pela vontade do administrador “capable de distinguer entre le bien et le mal, présente avant tout le caractère d'un jugement de moralité" (p. 19).

A noção de ordem pública supõe a proteção da ordem moral, de tal modo que, no diagnóstico de RENÉ CHAPUS, a jurisprudência consagra o entendimento de que "la moralité publique est la quatrième composante de la notion de l'ordre public" (Droit Administrative Général - tomo I - 9a edição - 1995 - p. 620).

VEDEL, com base na construção jurisdicional do direito administrativo, admite que "sous couvert de "l'espirit" de la loi, ou sous couvert des principes généraux du droit, le juge aministratif intègre des directives de moralité à la legalité" (Droit Administratif - 6a edição - 1976 - p. 610/611).

A vinculação do administrador aos objetivos éticos, que são o pressuposto de sua competência, impõe-lhe, a par da motivação de seus atos, a demonstração da "sinceridade dos motivos" na expressão de BERNARD PACTEAU, como condição de validade de sua conduta. A ausência desta característica pode conduzir à afirmação de erro manifesto como espécie de desvio de poder (Le juge de l'excès de pouvoir et les motifs de l'acte administratif - 1977 - p. 121 e passim).

\section{IV}

No direito brasileiro, o estudo da moralidade administrativa tem como expressão pioneira a clássica monografia de MANOEL DE OLIVEIRA FRANCO SOBRINHO 
que aprofundou a análise do tema (O controle da moralidade administrativa 1974). O mesmo autor voltou à demonstraçâo alualizada da tese em contribuição ao Seminário Nacional de Direito Administrativo. em 1992 (Revista de Direito Administrativo, vol. 190. p. 247) e renova sua posição em ensaio sobre "Ética e moralidade nos procedimentos administrativos" que enriquece a recente obra coletiva em homenagem a Miguel Marienhoff que acaba de ser editada na Argentina (Derecho Administrativo 1998 - p. $635 / \mathrm{s}$.).

De nossa parte, em tese oferecida em 1951, ao concurso para livre docente de Direito Administrativo da Faculdade de Direito do Rio de Janeiro (atual Faculdade de Direito da UERJ), anotávamos que a finalidade da competência administrativa coloca razões de moralidade entre os objetivos de interesse público que conferem ao conceito de legalidade um conteúdo sociológico na medida em que a lei "reflete e corporifica as tendências do meio social" (Desvio de Poder em matéria Administrativa - incorporada ao nosso livro "Temas de Direito Público" — edição Renovar - 1997 - tomo I, pág. 101).

Voltamos, em estudo posterior, à avaliação da moralidade administrativa perante a lei do Tribunal de Contas da União (Revista de Direito Administrativo - 1992 — vol. 190, pág. 45).

Diogo Figueiredo Moreira Neto, em completo e valioso estudo, cuidou da "Moralidade administrativa - Do conceito à efetivação" (Revista de Direito Administrativo, vol. $190-1 / 44$ ) e Carmem Lucia Antunes Rocha dedicou extenso e documentado capítulo de seus "Princípios constitucionais da administração Pública" à moralidade administrativa (ob. cit. p. 187/235).

Igualmente Maria Sylvia Zanella di Pietro versou a matéria no excelente manual de "Direito Administrativo" (5ª edição - 1994 - p. 69/71), antes desenvolvida na tese com que conquistou a cadeira na Faculdade de Direito da USP (Discricionariedade administrativa $-190-$ p. 98/118).

São igualmente destacadas as contribuições ao tema nos estudos de Hely Lopes Meireles (Direito Administrativo Brasileiro - 19a edição - p. 83/85 - p. $96 \mathrm{em}$ que alude à "violação moral da lei" com expressão do desvio de finalidade); Celso Antonio Bandeira de Mello (Curso de Direito Administrativo - $4^{\mathbf{a}}$ edição - p. 59/60) e Seabra Fagundes em artigo sobre Ação Popular (Revista Forense - vol. 112, p. 13).

A incidência do "Princípio da moralidade no direito tributário" foi especialmente avaliada na coletânea de colaborações coordenada por Ives Gandra da Silva Martins ( $2^{\mathrm{a}}$ edição atualizada - 1998) e mereceu estudos especiais de Lucia Valle Figueiredo (Estudos em homenagem a Geraldo Ataliba - vol. 2 - p. 419/433, "O princípio da moralidade administrativa e o direito tributário") e de Ricardo Lobo Torres "Moralidade e Finanças Públicas", in "Estudos em homenagem ao prof. Caio Tácito" - 1997 - p. 525/561, com reconhecimento da jurisprudência e do direito comparado. Do mesmo autor, o ensaio sobre "Ėtica e Justiça Tributária" (in Direito Tributário - Estudos em homenagem a Brandão Machado - 1998 - pág. 175/196).

Merece especial referência pelo reflexo nos estudos da matéria entre nós, o substancial ensaio de Antonio José Brandão, advogado em Portugal, sobre "Moralidade administrativa" (Revista de Direito Administrativo - vol. 25, p. 454/467). 
A conceituação constitucional da matéria inspirou amplo exame da questão por José Augusto Delgado. ilustrado com o apelo à jurisprudência ("O princípio da moralidade administrativa e a Constituição de 1988" - Revista dos Tribunais vol. 680 - p. 34/46).

Em ensaio dedicado à "Ética e Administração Pública" (Edição Revista dos Tribunais - 1993) Maurício Antonio Ribeiro Lopes desenvolveu o conceito da moralidade administrativa.

O longo passeio pela presença, na doutrina e na normatividade, do princípio da moralidade administrativa abona sua consagração e atualidade como instrumento de controle da legalidade e da legitimidade da conduta da Administração Pública.

Os atos administrativos são submetidos, por definição, à observância da finalidade a que se destina a competência do administrador. E, para o diagnóstico deste necessário casamento, prepondera o exame da existência real dos motivos determinantes do ato a serem inspirados por objetivos de justiça social e de moralidade pública.

Em síntese, o princípio da moralidade administrativa pressupõe exame dos motivos do ato administrativo em conexão com o vínculo legal à finalidade legítima da competência.

Se o administrador coloca seus poderes a serviço de interesses pessoais exclusivos ou de conceitos que discrepam de valores morais respeitáveis, o ato administrativo, ainda que aparentemente válido, se torna viciado e passível de anulação por desvio de finalidade.

A Constituição de 1988, tornando explicita a subordinação da legalidade ao efetivo respeito à moralidade administrativa, incorporou, definitivamente, ao direito positivo nacional, a construção doutrinária cuja antecedência cuidamos de documentar.

É expressivo destacar que a recente Lei $n^{2} 9.784$, de 29 de janeiro de 1999, regulando o processo administrativo no âmbito da Administração Pública Federal, arrola, entre os princípios de observância obrigatória pela Administração Pública, a garantia da moralidade (art. $2^{\mathfrak{Q}}$ ).

Assim igualmente prescreve a contemporânea lei do processo administrativo do Estado de São Paulo, em seu artigo 4o (Lei no 10.1777, de 30 de dezembro de 1998).

Será auspicioso que a legislação de outros Estados acompanhe, neste e em outros aspectos, a sistemática do processo administrativo, contribuindo para a prática adequada da boa administração.

A imoralidade administrativa não é causa de anulação do ato administrativo quando se possa evidenciar a autonomia entre os motivos da conduta do administrador.

A exigência ou aceitação de propina para a prática de ato legalmente válido conduzirá à responsabilidade administrativa — ou até mesmo penal - sem que necessariamente se contamine a legalidade da prestação administrativa. 
Admita-se. a título de exemplo, que licitante au qual foi regularmente adjudicado determinado serviço. pela oferta da melhor proposta. seja compelido ao pagamento de vantagem indevida para obter a celebração do contrato.

A concussão ou corrupção administrativa. passível de sanção, não obrigará. em tal caso. à anulação do contrato celebrado com observância do procedimento adequado.

O anedotário forense registra a praxe de um juiz que condicionava a sentença ao pagamento prévio de uma propina. Todavia, fazia preceder a exigência do estudo rigoroso dos autos de modo a determinar a parte portadora do direito a ser garantido.

E somente dela recebia vantagem para liberação da sentença, na qual identificava sua compatibilidade com a correta afirmação da justiça. A validade da sentença não legitimava, em suma, a imoralidade funcional, nem esta tornava nula a justa prestação jurisdicional.

Na maioria dos casos, porém, a influência do fator moral conduz à falsa motivação do ato e, portanto, à sua conseqüente nulidade, sem prejuízo da responsabilidade administrativa ou penal pertinente. 